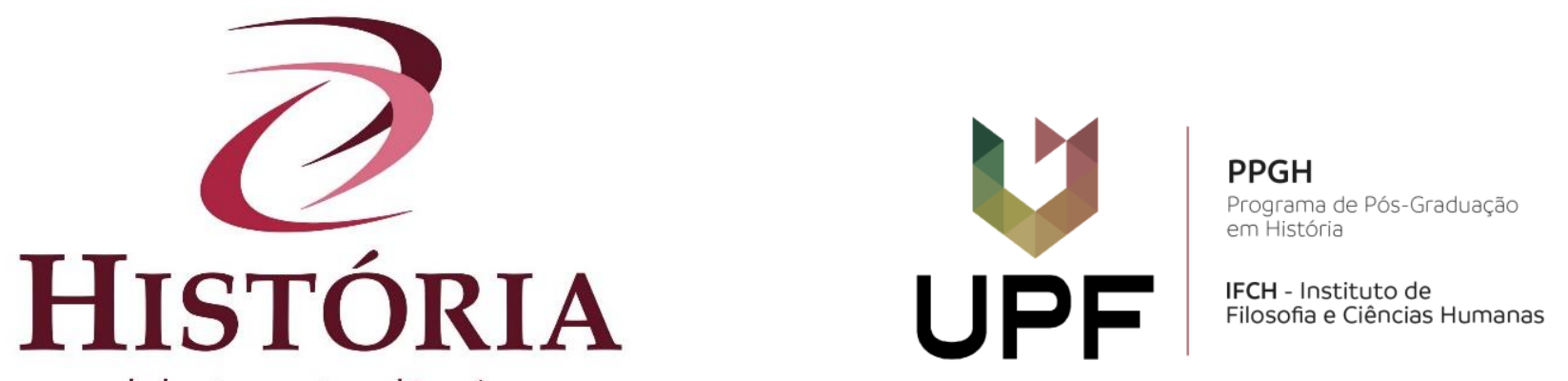

debates e tendências

\title{
Los inmigrantes alemanes de la Argentina y sus escritos
}

\author{
Os imigrantes alemães na Argentina e seus escritos
}

\section{German immigrants from Argentina and their writings}

\author{
Claudia Beatriz Garnica de Bertona ${ }^{\mathrm{i}}$
}

Resumen: La inmigración de germanohablantes a la Argentina es una cuestión que recién en este siglo ha comenzado a estudiarse de manera panorámica y sistemática y no solamente a través de casos aislados. Mi trabajo formula hipótesis sobre esta cuestión a la vez que se refiere a la investigación de los diferentes tipos de discursos de los inmigrantes. La relación de ellos con la literatura nacional argentina es otro de los temas de mi trabajo, ya que hasta ahora permanecen fuera del canon, como un susbsistema apenas visible y sin presencia en el sistema literario argentino.

Palabras clave: Migración. Literatura de minorias. Canon literario nacional.

Resumo: A imigração de falantes de alemão para a Argentina é uma questão que só neste século começou a ser estudada de forma panorâmica e sistemática e não apenas através de casos isolados. O meu trabalho formula hipóteses sobre esta questão ao mesmo tempo que se refere à investigação dos diferentes tipos de discursos dos imigrantes. Sua relação com a literatura nacional argentina é outro dos temas de minha obra, já que até agora permanecem fora do cânone, como um subsistema pouco visível e sem presença no sistema literário argentino.

Palavras chave: Migração. Literatura minoritária. Cânone literário nacional

\begin{abstract}
The immigration of German speakers to Argentina is an issue that only in this century has begun to be studied in a panoramic and systematic way and not only through isolated cases. My work formulates hypotheses on this question while at the same time referring to the investigation of the different types of discourses of immigrants. Their relationship with Argentine national literature is another of the themes of my work, since until now they remain outside the canon, as a barely visible subsystem and without presence in the Argentine literary system.
\end{abstract}

Keywords: Migration. Minority literatura. National literary canon. 
Mi trabajo se propone ofrecer una introducción sobre la inmigración alemana a la Argentina, en la que me referiré también al estado de la cuestión sobre la misma. Seguiré luego con una descripción de la investigación central que realizo, de la que se desprenden cuestiones teóricas, metodológicas y también problemáticas que están aún sin resolver.

En primer lugar, debo decir que la migración alemana a la Argentina no ha sido un fenómeno muy favorecido por la investigación académica. De hecho, el único estudio abarcador sobre el fenómeno pertenece a una germanista y politóloga de la Sorbona, Anne Saint Sauveur-Henn, quien en 1995 publicó en francés su tesis doctoral titulada Un siglo de inmigración alemana a la Argentina (1853-1945). Antes de ella hubo estudios parciales sobre sectores migratorios o trabajos de divulgación, dirigidos a un público no especialista y con una carga ideológica que se fue suavizando en las respectivas reediciones como la obra de Lütge, Hoffmann y Klingenfuss, Alemanes en la Argentina 1520-1980, que fue reeditada en 2017 por Regula Rohland de Langbehn. Este último texto tiene como punto de partida la presencia de Ulrico Schmidl, el primer cronista sobre la Argentina, quien participó en la expedición de Pedro de Mendoza y la fundación de Buenos Aires y trata de mostrar cómo la presencia alemana, si bien escasa en número frente a otras migraciones, ha desempeñado un papel de gran importancia en la formación de la nación argentina. El tono nacionalista de la primera edición se vuelve más neutro en ediciones posteriores. Aporta mucha información de utilidad pero no tiene el grado de profundidad y de documentación que ostenta el estudio de Saint Sauveur. Hay también una decena de estudios parciales desde el ámbito académico como los de Holger Meding, quien estudia la emigración de los nazis a la Argentina o Ronald Newton, autor de El cuarto lado del triángulo. La amenaza nazi en la Argentina (1995) y de German Buenos Aires, 1900-1933. Social Change and Cultural Crisis (1977). Más recientemente, las investigaciones de Cecilia Gallero sobre las colonias alemanas Monte Carlo y Puerto Rico en Misiones y las de Germán Friedmann sobre los alemanes antinazis de Argentina, o la del investigador candiense Benjamin Bryce, To Belong in Buenos Aires: Germans, Argentines, and the Rise of a Pluralist Society, profundizan aspectos históricos específicos del fenómeno migratorio alemán en la Argentina y son el testimonio claro de que la investigación sobre la inmigración alemana a la Argentina se encuentra en pleno proceso de realización.

Probablemente la ausencia de archivos en los que se encuentre el material reunido y procesado haya sido la causa de que estos estudios recién estén comenzando a 
tener un lugar dentro de la investigación académica y se hayan constituido en el tema de tesis doctorales, entre las que se incluye la mía sobre Literatura en lengua alemana de migrantes y viajeros a la Argentina (1870-1970), publicada en Alemania en 2016. Desde el año 2012 existe el Centro DIHA (Centro de Documentación de la Inmigración de Habla Alemana en la Argentina), que obtuvo personería jurídica en 2016 y funciona en la Universidad Nacional de General San Martín. Este centro surgió de la iniciativa de Regula Rohland de Langbehn, quien reunió los materiales, los acopió y clasificó y encontró en la UNSAM un lugar propicio para su catalogación y conservación. Su finalidad fundamental es preservar a través de documentos la memoria de la inmigración de lengua alemana en la Argentina. Algunas de las actividades de este centro son la organización anual de un coloquio con una temática específica, por ejemplo iglesias, instituciones, etc. y la publicación de los Cuadernos del Centro DIHA, en los que se incluyen tanto investigaciones como traducciones. Como es evidente, Brasil lleva a la Argentina una gran ventaja en la investigación y recopilación de fuentes de investigación de este fenómeno.

La inmigración alemana a la Argentina tuvo características particulares frente a otros países, ya que se trató de una inmigración básicamente urbana, que ha dejado su impronta fundamentalmente en Buenos Aires, donde se concentró la mayor densidad de migrantes alemanes. Por ejemplo, Saint Sauveur afirma que entre 1936 y 1940 Capital Federal y provincia de Buenos Aires polarizan el 95\% de la inmigración alemana. Si bien hubo varios intentos de incluir a los inmigrantes dentro del sistema de colonias, estas en general no obtuvieron los resultados esperados a lo largo del tiempo. $\mathrm{O}$ bien los colonos dejaron de serlo y se trasladaron a la ciudad, o bien se quedaron en ellas, pero las colonias se comportaron como estructuras abiertas, lo que contribuyó a la pérdida de un carácter germánico específico para las mismas. La voracidad de algunos de los responsables de las agencias de colonización y el desinterés del estado argentino por controlar su funcionamiento, sumado al hecho de que la mayoría de los colonos desconocía de manera casi absoluta la cuestión de la labranza de la tierra, y mucho menos en condiciones altamente hostiles derivadas del tipo de suelos, de cultivos, de enfermedades y plagas, fueron las razones que llevaron a la mayoría de las empresas colonizadoras al fracaso. Las únicas colonias que guardan un cierto carácter germano, que se hace muy evidente en setiembre en una fiesta de la colectividad, es la de los Alemanes del Volga en Entre Ríos. Curiosamente, para el resto de los germanohablantes que migraron a la Argentina, los alemanes del Volga no eran considerados como alemanes sino como rusos, o a lo 
sumo rusoalemanes, y no gozaban de prestigio dentro de la comunidad. Lo expuesto plantea diferencias importantes con la inmigración alemana de Brasil y Chile, donde el sistema de colonización representó un modelo más exitoso.

$\mathrm{Al}$ establecerse en la ciudad, los inmigrantes deben, por razones de supervivencia, comenzar a trabar relaciones con la comunidad de destino, entre las cuales resulta fundamental el aprendizaje del idioma, aunque algunos de ellos, a pesar de haber vivido más tiempo en la Argentina que en su país de origen, nunca llegaron a concretarlo de manera absoluta. Rápidamente los germanohablantes se organizaron en sociedades religiosas, deportivas y culturales y comenzaron a notarse dentro del concierto de migrantes que era posible distinguir en la Argentina en la primera mitad del siglo XX. En este sentido es destacable el papel que desempeñan las sucesivas generaciones de la familia Alemann, de origen suizo. Johann Alemann funda hacia fines del siglo XIX el diario alemán que hoy todavía se publica, aunque como semanario: el Argentinisches Tageblatt, que constituyó una vía importante de publicación para periodistas y escritores, a la vez que fue uno de los bastiones de la resistencia antinazi en la Argentina. En este periódico se desarrolla un concepto de germanidad (Deutschtum) en sentido amplio, que asume a todos los germanohablantes sin distinción de origen. Claramente Johann y luego su hijo Theodor tienen la esperanza de crear una especie de islas de germanidad en el territorio argentino, en las que se puedan preservar el idioma y las costumbres germanas. Esto, que resultaba atractivo para los inmigrantes, quienes a pesar de habitar otro suelo pretendían habitar idealmente un tercer espacio en el que no perdieran los elementos que consideraban como parte de su identidad, fue imposible de llevar a la práctica. Los otros descendientes, Ernesto y actualmente su hijo Roberto, suavizaron esta idea de germanidad y fundamentalmente el primero, trabajó de manera abierta en la oposición al Nacionalsocialismo, aun cuando esto representó para el diario el boicot de empresas alemanas alineadas que dejaron de publicar propaganda o la pérdida de un buen número de suscriptores que se sentía más a gusto leyendo el Deutsche-La Plata Zeitung, que defendía de manera abierta al gobierno de Hitler.

Anne Saint Sauveur distingue tres fases en la inmigración alemana a la Argentina: la primera, de 1810 a 1860, a la que llama fase premigratoria. No se trata de una corriente continua, sino de casos aislados. Predominan en esta etapa comerciantes, artesanos y soldados. Fundamentalmente los primeros entran en competencia comercial con los ingleses, que habían llegado antes y pretendían reemplazar el papel que había tenido España hasta entonces en el comercio monopólico. La motivación para la 
emigración responde en esta fase a razones económicas y se puede hablar de cierta homogeneidad en el grupo migratorio, aunque ya es posible distinguir diferencias originadas en el nivel económico de los inmigrantes. Los que llegan a la Argentina con dinero para invertir logran integrarse a la vida comercial e industrial y se relacionan con la elite rica de Buenos Aires. En esta época no hay una política de estado en relación con la inmigración y comienzan a llegar los rusoalemanes y los habitantes de las primeras colonias. Los datos son muy difíciles de procesar ya que no existía un procedimiento de registro unificado en el puerto de Buenos Aires y, por otra parte, un buen número de inmigrantes alemanes llegó a las colonias de Misiones a través de Brasil.

En la segunda fase, que va de 1860 a 1933 es posible encontrar una comunidad mayor en número y más activa, caracterizada por la diferenciación social y la fundación de asociaciones. Los inmigrantes ya no son grandes capitalistas sino que pertenecen a la clase media. Se trata de científicos y de quienes ejercen profesiones liberales. La fundación del II Reich en 1871 contribuye a crear entre los alemanes de Argentina conciencia de nación. La Primera Guerra golpea a esta minoría alemana: algunos deciden remigrar para defender a la patria en peligro. Los que se quedan, aumentan su conciencia de pertenecer a una minoría. Los festejos del Primer centenario en 1910 y la renovación de lazos con la entonces llamada "madre patria", es decir, España, es significativa en el sentido de que en un momento de serios interrogantes sobre el ser nacional, quienes tienen en su poder la posibilidad de delinear desde el estado los rasgos fundantes de la nación, se inclinan por la renovación de la identidad hispánica y de los lazos coloniales, en lugar de integrar ya entonces una realidad tan clara como era la presencia de inmigrantes de variados orígenes en todo el territorio argentino, pero de manera evidente e innegable, en la Capital Federal y la provincia de Buenos Aires. La finalización de la guerra y la fundación de la República de Weimar llevan a la división entre monarquistas y republicanos dentro de la comunidad alemana en la Argentina.

La tercera y última fase va de 1933 a 1945. Durante el Nacionalsocialismo se extiende entre los alemanes de Argentina la sensación de pertenecer a un gran imperio. Cambia su autopercepción, ya que el sentimiento de una minoría poco integrada se reemplaza con el de pertenecer a un pueblo llamado a dominar el mundo, que también puede valerse para ello de los alemanes que ya se encuentran diseminados por diferentes países y que, en parte, saludan con alegría la llegada del líder que cumplirá el gran destino al cual estaban llamados, según creían. Esta situación, como ya dije, provoca divisiones entre inmigrantes nazis y antinazis. Es la época en que se produce el caudal más 
importante de inmigración judía a la Argentina. En 1945, cuando Argentina declara la guerra a Alemania, muy poco antes de su finalización, se produce la confiscación de bienes alemanes, que recién completan su restitución hacia 1955.

La política argentina, que se había mostrado particularmente receptiva hacia la inmigración de anglosajones durante la presidencia de Sarmiento, no se mantiene constante al respecto. Y cuando los colonizadores de la actual provincia de Santa Fe protagonizan revueltas hacia 1893 por el reclamo de mayores derechos civiles, el estado cae en la cuenta de que los trabajadores que habían llegado eran además personas que exigían una mejor consideración del estado al que tributaban. A partir de allí quienes gobiernan caen en la cuenta de la amenaza que representan los inmigrantes en la formación de una nación que tiene un pasado muy breve y se encuentra en la búsqueda de su identidad. La reacción más inmediata es la renovación de los lazos con España y la desconfianza hacia los elementos foráneos, a los que no se integran en un proyecto de nación multicultural sino que se aíslan como un elemento extranjero que, particularmente para los nacionalistas de la década de 1930, debe ser contenido y mantenido fuera de la constitución del así llamado "ser nacional".

Mientras que las cuestiones políticas del país de origen y del de destino rozan la cotidianeidad de la vida de los inmigrantes alemanes, muchos de ellos se dedican a dejar testimonios escritos. Algunos pocos eran ya escritores antes de su partida, pero la mayoría se convierten en escritores en la Argentina. Los textos más abundantes son los autorreferenciales, en los que se narran experiencias de migración. Podríamos incluir dentro de estos un número significativo de textos de viaje, en los que el discurso descriptivo sobre lo que el viajero observa es predominante. Por lo general, los viajeros son subvencionados por estados alemanes, por ejemplo Prusia, que envía a especialistas como topógrafos o geógrafos para analizar las posibilidades de Argentina como destino de colonización. Las memorias, autobiografías y relatos de viaje, así como las descripciones del país hechas para futuros colonizadores tienen un papel fundamental en la literatura en lengua alemana a la Argentina. Aunque también se escribe ficción, lírica y teatro, la preponderancia de la literatura del yo es muy evidente.

La investigación de la literatura en alemán escrita en la Argentina no tuvo hasta 2014 un estudio abarcador y panorámico. Sí existían estudios parciales, de autores o temas, pero no una reconstrucción del proceso histórico para visibilizarlo y evitar que los materiales perecieran en alguna biblioteca personal o quedaran olvidados en los estantes de bibliotecas alemanas. La recolección de materiales, que restringí en mi investigación 
a obras publicadas tanto en Argentina como en Alemania en una editorial no propia, fue una tarea sumamente compleja y lenta, que me permitió generar un corpus de más de 400 obras y de 107 autores. Con esa evidencia documental es innegable que la Argentina tuvo una literatura escrita en alemán, lo que es ya un proceso cerrado, cuyos límites temporales establecí entre 1870 y 1970 . Reconstruí la biografía de los autores, siempre que fue posible y analicé los textos que consideré debían incluirse dentro del corpus de la investigación, lo que no fue una tarea fácil debido a la lejanía en el tiempo, en algunos casos, y a la dificultad para acceder a los materiales, en otros.

La comprobación de la existencia de una literatura en lengua alemana de la Argentina es un fenómeno que prefiere ser ignorado por la literatura vernácula, que prefiere construir su canon en base a textos escritos en el territorio nacional en castellano. Este concepto monolingüe y geográfico es fácilmente refutable si se toma en cuenta que uno de los escritores consagrados de la literatura argentina como Julio Cortázar compuso la mayor parte de su obra siendo un vecino de París, o si se acepta que existen en la Argentina minorías linguiísticas que de manera reciente comienzan a ser investigadas y visibilizadas como la mapuche, que posee una literatura de tradición oral que se está fijando por escrito y traduciendo recién ahora, o la minoría galesa y sus descendientes, que habitan la Patagonia y mantienen las costumbres y el idioma. Aceptar la existencia de minorías y de sus escritos es un proceso que se está iniciando y que seguramente llevará en algún momento a la revisión del concepto mismo de literatura argentina y, más allá todavía, de la definición de la identidad nacional. Las teorías poscoloniales, fundamentalmente a través de Walter Mignolo y Beatriz Sarlo, así como la Teoría de los Polisistemas, son funcionales para dar una base teórica a este tipo de investigaciones, que destruyen la construcción de una cultura nacional sin fisuras ni elementos extraños. No se puede negar la evidencia, los documentos, los textos de los inmigrantes, que pertenecen tanto al sistema de origen, que también los ignora, como al de destino. La literatura alemana, marcada por emigraciones, inmigraciones y exilios, no puede ni debe ignorar la existencia de las minorías que escribieron en alemán desde otros países ¿Cuál es el lugar de esta literatura "sin residencia fija", como la llama Ottmar Ette? Quizás la respuesta esté en su obra Literatura en movimiento. Espacio y dinámica de una escritura transgresora de fronteras en Europa y América, de 2008. Con una cita de él me gustaría cerrar mi trabajo, cuando afirma:

Los nuevos movimientos (...) se están apoderando del espacio y demandando nuevas formas de pensamiento y perspectivas para su análisis. Esto corresponde especialmente, me parece, a las concepciones y a los conceptos que se dedican a las espacialidades 
transformadas y en proceso de cambio. Al lado de una convivencia multicultural y una mezcla y reciprocidad interculturales - y lo siguiente es para mí muy positivo - se ha instalado un entrevero transcultural en el cual las más diversas culturas se penetran recíprocamente y se modifican. Los lugares de residencia fijos de las culturas en su mayor parte pertenecen al pasado (ETTE, 2008, p. 15-16).

\section{Referencias}

BRYCE, Benjamin. To Belong in Buenos Aires: Germans, Argentines, and the Rise of a Pluralist Society. Stanford: University Press, 2018.

ETTE, Ottmar. Literatura en movimiento. Espacio y dinámica de una escritura transgresora de fronteras en Europa y América. Madrid: Consejo Superior de Investigaciones Científicas, 2008.

FRIEDMANN, Germán. Alemanes antinazis en la Argentina. Buenos Aires: Siglo XXI, 2010.

GALLERO, Cecilia. Con la patria a cuestas: la inmigración alemana-brasilera en la colonia Puerto Rico, Misiones. Buenos Aires: Araucaria editora, 2009.

GARNICA DE BERTONA, Claudia. Literatura en alemán de migrantes y viajeros a la Argentina (1870-1970). Un capítulo de las relaciones germanoargentinas. Saarbrücken: Publicia. 2016

LÜTGE, Wilhelm (et. all.). Los alemanes en la Argentina. 500 años de historia. Traducción y edición a cargo de Regula Rohland de Langbehn. Buenos Aires: Biblos, 2017

MEDING, Holger. La ruta de los nazis en tiempos de Perón. Buenos Aires: Emecé, 1999.

NEWTON, Ronald. German Buenos Aires, 1900-1933. Social Change and Cultural Crisis. Austin and London: University of Texas Press, 1977.

NEWTON, Ronald. El cuarto lado del triángulo. La "amenaza nazi" en la Argentina (1931-1947). Buenos Aires: Sudamericana, 1995.

SAINT-SAUVEUR-HENN, Anne. Un siecle d' emigration allemande vers l' Argentine 1853-1945. Köln/Weimar/Wien: Böhlau Verlag, 1995.

SAINT-SAUVEUR-HENN, Anne. Exotische Zuflucht? Buenos Aires, eine unbekannte und vielseitige Exilmetropole“. En: KROHN, Claus-Dieter (et.all.). Exilforschung. Ein internationales Jahrbuch. Band 20: Metropolen des Exils. München: Text +kritik, 2002.

Recebido: 10/03/2019

Aceito: $14 / 04 / 2019$

Publicado: 13/05/2019

' Profesora, Licenciada y Doctora en Letras. E-mail: claudiagbertona@gmail.com 